\title{
Effects of Limiting Medicaid Drug-Reimbursement Benefits on the Use of Psychotropic Agents and Acute Mental Health Services by Patients with Schizophrenia
}

\section{Citation}

Soumerai, Stephen B., Thomas J. McLaughlin, Dennis Ross-Degnan, Christina S. Casteris, and Paola Bollini. 1994. "Effects of Limiting Medicaid Drug-Reimbursement Benefits on the Use of Psychotropic Agents and Acute Mental Health Services by Patients with Schizophrenia." New England Journal of Medicine 331 (10) (September 8): 650-655. doi:10.1056/ nejm199409083311006.

\section{Published Version}

doi:10.1056/NEJM199409083311006

\section{Permanent link}

http://nrs.harvard.edu/urn-3:HUL.InstRepos:32696158

\section{Terms of Use}

This article was downloaded from Harvard University's DASH repository, and is made available under the terms and conditions applicable to Other Posted Material, as set forth at http:// nrs.harvard.edu/urn-3:HUL.InstRepos:dash.current.terms-of-use\#LAA

\section{Share Your Story}

The Harvard community has made this article openly available.

Please share how this access benefits you. Submit a story.

\section{Accessibility}




\title{
SPECIAL ARTICLE
}

\section{EFFECTS OF LIMITING MEDICAID DRUG-REIMBURSEMENT BENEFITS ON THE USE OF PSYCHOTROPIC AGENTS AND ACUTE MENTAL HEALTH SERVICES BY PATIENTS WITH SCHIZOPHRENIA}

\author{
Striphen B. Soumerai, Sc.D., Thomas J. Mcilauginin, Sc.ID., Dlennis Ross-Degnan, Sc..D., \\ Giristina S. Cinstitieis, M.S., and PaOla Bollini, M.D., Dr.P.H.
}

\begin{abstract}
Background. We examined the effects of a three-prescription monthly payment limit (cap) on the use of psychotropic drugs and acute mental health care by noninstitutionalized patients with schizophrenia. We hypothesized that reducing access to such drugs would increase the use of emergency mental health services and the rate of partial hospitalizations (full-day or half-day treatment programs) and psychiatric-hospital admissions.

Methods. We linked Medicaid claims data for a period of 42 months with clinical records from two community mental health centers (CMHCs) and the single state psychiatric hospital in New Hampshire, where Medicaid imposed a three-prescription limit on reimbursement for drugs during 11 months (months 15 through 25) of the study. For comparison, we used Medicaid claims for a period of 42 months in New Jersey, which had no limit on drug reimbursement. The study patients $(n=268)$ and the comparison patients $(n=1959)$ were permanently disabled, noninstitutionalized patients with schizophrenia, 19 through 60 years of age, who were insured by Medicaid. We conducted interrupted time-series regression analyses to estimate the effects of the cap on the use of medications and mental health services.
\end{abstract}

$\mathrm{R}^{\mathrm{r}}$ EQUIREMEN'TS for cost sharing by paticnts and limitations on coverage for primary medical care are popular cost-containment strategies in the United States and other countries ${ }^{1-3}$; they may become more prevalent as a result of future health insurance reforms. Yet objective data on the effects of these measures on the use, costs, and outcomes of health care in vulnerable populations are limited. ${ }^{4-f}$ We examined the effects of limits on Medicaid payments for drug treatment on access to effective pharmacotherapy and on the use of acute mental health care services among low-income, noninstitutionalized patients with schizophrenia.

The economic, clinical, and personal burdens associated with schizophrenia make it a leading public: health problem. 'The lifetime prevalence of schizophrenia is between 0.5 percent and 1.0 percent ${ }^{7-9}$; rates of mortality and somatic morbidity are much highcr among patients with schizophrenia than in the general population ${ }^{10}$; and the total costs to society are estimated to equal half the total financial burden of myocardial infarction. " Patients with schi\%ophre-

From the Departments of Ambulatory Care (S.B.S., T.J.M., D.R.-D., C.S.C.) and Prevention and Social Medicine (I).R.-1).), Harvard Medical School and Harvard Community Health Plan, Boston; and the International Organization for Migration, Geneva (P.B.).

Supported by a grant (R()1MI-144881) from the National Institute of Mental Health and by the Agency for Health Care Policy and Research, the Rohert Wood Johnson Foundation, and the Harvard Community Health Plan Foundation.
Results. The cap resulted in immediate reductions (range, 15 to 49 percent) in the use of antipsychotic drugs, antidepressants and lithium, and anxiolytic and hypnotic drugs $(P<0.01)$. It also resulted in coincident increases of one to two visits per patient per month to CMHCs (range of increase, 43 to 57 percent; $P<0.001$ ) and sharp increases in the use of emergency mental health services and partial hospitalization (1.2 to 1.4 episodes per patient per month), but no change in the frequency of hospital admissions. After the cap was discontinued, the use of medications and most mental health services reverted to base-line levels (measured in the first 14 months of the study). The estimated average increase in mental health care costs per patient during the cap $(\$ 1,530)$ exceeded the savings in drug costs to Medicaid by a factor of 17.

Conclusions. Limits on coverage for the costs of prescription drugs can increase the use of acute mental health services among low-income patients with chronic mental illnesses and increase costs to the government, even aside from the increases caused in pain and suffering on the part of patients. (N Engl J Med 1994;331: 650-5.)

nia are also highly likely to receive fragmented and uncoordinated care. ${ }^{12-15}$

Antipsychotic drugs, the most effective treatment for acute episodes or exacerbations of schizophrenic illness, ${ }^{16,17}$ allow many patients to leave institutions and live in the community. ${ }^{18,19}$ Rates of relapse among patients with schizophrenia who receive medication are two to three times lower than those among patients receiving placebo, ${ }^{16,20}$ and noncompliance increases the frequency of acute psychotic episodes and psychiatric hospitalization. ${ }^{16,17}$ Although antipsychotic drugs can have serious adverse effects, ${ }^{19,21}$ many clinicians prescribe them at moderate doses for as long as possible to prevent relapse. In addition to antipsychotic agents, patients with schizophrenia may receive lithium, antidepressants, or benzodiazepines for concomitant psychiatric disorders. ${ }^{16}$

Nine states limit the number of prescriptions per patient per month that are reimbursed by Medicaid, but there are no data on the effects of such caps on people with chronic mental illnesses. In September 1981, the New Hampshire legislature limited Medicaid reimbursement to three prescriptions per month as a cost-cutting measure during a budget crisis that was precipitated, in part, by reduced federal support for the Medicaid program. ${ }^{5}$ Patients who filled more than three prescriptions in any month were usually unable to pay for them out of pocket ${ }^{22}$; this policy therefore reduced the use of essential medications (such as insulin and cardiac drugs) among elderly patients with 
chronic discases and increased nursing home admissions." Eleven months later, alter litigation by Now Hampshire lecgal Assistance, a public legal-aid agency, the state replaced the calp with a \$l-perprescription copayment.

We undertook this study to determine whether the limit on drug reimbursement was followed by reductions in the use of antipsychotic agents, drugs for mood disorders, and anxiolytic and hypnotic agents and by an increase in the use of mental health services among low-income adults with schizophrenia. We hypothesized that financial restrictions on access to psychotropic drugs would adversely affect the mental health of these patients. 'The resulting increase in agitation and in the frequency of psychotic episodes would increase the need for emergency mental health services and partial hospitalization (full-day or halfday treatment programs) at community mental health centers (CMHCis) and the frequency of admissions to psychiatric hospitals, thereby shifting costs from the federal-state Medicaid program to state menti.l health programs.

\section{Methods}

In this study we evaluated the effects of the cap with use of an interrupted time-series design (with and without compartison series), one of the strongest quasi-experimental de signs. ${ }^{232-1}$ We determined rates of medication use before the cap was implemented (for a period of 14 months), during its application (11 months), and affer it was discontimued (17 months) in a cohort of adult patients with schizophernia in New Hampshire and in an identically defined comparison cohort in New Jersey, which bad no restrictions on drug reimbursement. In New Hampshire, we also measured changes in the use of acute mental health care services in association with the implementation and discontinuation of the cap.

\section{Sources of Data}

We used data fiom three sources to measure eflecets of policy changes: Nedicaid corollment and chams data, data on discharges from state psychiatric hospitals, and data on visits o CMHCis. Medicaid corollment files in both states (covering.July 1980 through Decomber 1983) included age, lace, sex, and monthly calegory of curollment (c.g., Aid to the Permancmtly and Totally Disabled). Medicated drug-claims files combaned reliable data for individual patients on the identity of each medication, the date it was dispensed, the number of units, and the dose. 22,25-27

Virtually all psychiatric admissioms of pattents with schizophereniat during the study period were to New Hampshire's single state psychiatric hospital. Since Medicaid did not cover most of these admissions, we collected data from medical records on the dates of all hospitalizations of study patients during this period.

for a subgroup of the study cohort, we also obtained computerized data on all episodes of treatment at (:MHC:s. C:MHC: clinical data are more complete than Medicaid data, since they inchude all mental health services whether or not they ate covered by Medicaid. At two of the largest (iMHC is (designated (:MHC: 1 and C:MH(:2), which provided services to approximately one third of the study sample, we obluained data on the dates, changes, and category of service for routine visits as well as more intensive partial hospitalizations and emergency mental health services. At (:MHC: 1, where complete data were available, we abstracted from medical records the date, name, dose, and quantity of each antipsychotic drug prescribed or administered to study patients $(n=29)$; we also determined whether the prescription was paid for by Medicaid or porchased by the C:MHC:

\section{Study Cohorts}

The study eohorts in the two states were made up of pattents with schizeplerenia who lived in the community and were enrolled in
Medicaid. We used a previously validated algorithmen 10 identifi. pationts who had becu given a diagnosis of schizophrenia at least once as inpatients or twice as outpatients, according w Medicatd claims records during the base-line year (July 1980 through June 1981). To ensure that we studied patients who were severely disabled by sehizophrenia and to increase homogeneity between the study gromp and the comparison group), we repuired study patients to be enrolled in Medicaid's Aid to the Permanently and 'lotally Disabled program, to hate been enrolled for lo or more montles and not to have been admitted to a mursing home during the base-line year (and thus wo be exposed to the cap)), to be 19 through 60 years of age, and to be white (to control for the virtual absence of nonwhite pationts in Now Hampshire).

\section{Classification and Standardization of Use of Study Drugs}

We measured the rates of use of three types of psychotropic medication: antipsychotic agents, anxiolytic and hypmotic agents, and medications used to treat aflertive disorders (lithimm and antidepressimts). As previously reported, we created a standardized measure of use for each medication, the standard monthly dose (SMI)): for each study drug, one SMll) cepualed the mediati monthly dose received by ateh Medicatid pattent during the haseline year.

\section{Statistical Analysis}

We used segmented lincar-regression analysis $52,2 \%$ to estimate sudden changes in levels or trends in the time series of medication use (the number of SMI)s per enrolled patient in (each momth) and use of mental health services associated with the eap. We controlled for loss to follow-1u) (<8 percent during the 42 momths of the study) by including only the mumber of patients still comolled in Medicaid in the denominators for each monthly rate. Regression modeds included a constant term, a term for lincar time trend, and terms to estimate changes in the level or trend of service use that coincided with the introduction and discontinuation of the payment limit. ${ }^{29}$ $W^{\prime}$ e controlled for autocorrelation by assuming a first-order autoregeessive process (correlation between two consecutive observations), and we used residual analysis to test the adequatey of the resulting models. 52,226 We determined the statistical significance of regression coeflicients by means of ewo-tailed t-tests, and we estimated percent changes in the use of services during the period when the cap was in place as the observed use minus the expected use (on the basis of base-line trends) divided by the expecend use.

\section{Results}

\section{Characteristics of the Patients}

The base-line characteristics of the patients in the study cohort and the comparison cohort were similar ('lable 1). Forty-four percent of the study cohort and 46 percent of the comparison cohort received antipsychotic agents regularly $\geqslant 1$ prescription per quarter). About 30 percent of the patients in both cohorts received onc or more prescriptions for drugs to treat aflective disorders; 70 pereent of these prescriptions were for antidepressants, and 30 percent were for lithium. About 75 pereent of the patients in both cohorts received drugs from more than one catcgory.

\section{Changes in Medication Use}

Afer the introduction of the Medicaid cap in New Hampshire, there was a sudden drop in the level of reimbursed use of all threc categories of psychoactive medications (lig. 1). No changes in the level of use of the medications occurred in the New Jersey (compari- 
son) cohort, which received somewhat higher numbers of SMI)s of antipsychotic drugs and anxiolytic and hypnotic agents. Before the cap was implemented, the use of antipsychotic agents was stable at approximately $1.4 \mathrm{SMI}$ s per patient per month in New Hampshire; the level of use dropped abruptly by a mean ( $\pm \mathrm{SE}$ ) $0.23 \pm(0.08 \mathrm{SMD}$ ) during the cap (a decrease of 15.4 percent, $P=0.003$ ) but rose to a level slightly above pre-cap rates after the discontinuation of the policy. We also observed statistically signilicant reductions in the use of anxiolytic and hypnotic agents (a decrease of $0.07 \pm 0.02$ SMI) per patient per month $[37.3$ percent $\mid, P=0.001)$ and of ant $\mathrm{P}-$ depressants and lithium $(0.13 \pm 0.02 \mathrm{SMD}$ [49.1 percent ], $\mathrm{P}<0.001)$. 'The use of these drugs returned nearly to base-line levels after the discontinuation of the cap.

Among regular recipients of antipsychotic drugs, the level of use of these medications dropped by $0.64 \pm 0.15 \mathrm{SMD}$ per patient per month after the cap was instituted (a decrease in the level of 21.2 percent, $\mathrm{p}<0.001)$. The average monthly dose of antipsychotic drugs among regular recipients before the cap was $2.85 \mathrm{SMDs}$ ( $415 \mathrm{mg}$ of chlorpromazine or the equivalent per day), ${ }^{30}$ well within the accepted range of maintenance doses. ${ }^{22}$

\section{Provision of Medications in CMHCs}

Figure 2 shows a substantial increase in the amount of antipsychotic drugs administered to members of the study cohort at CMHC l after the cap was instituted. This change shifted costs for medications to the state mental health system. When both Medic-

Table 1. Base-Line Characteristics of the Study and Comparison Cohorts.

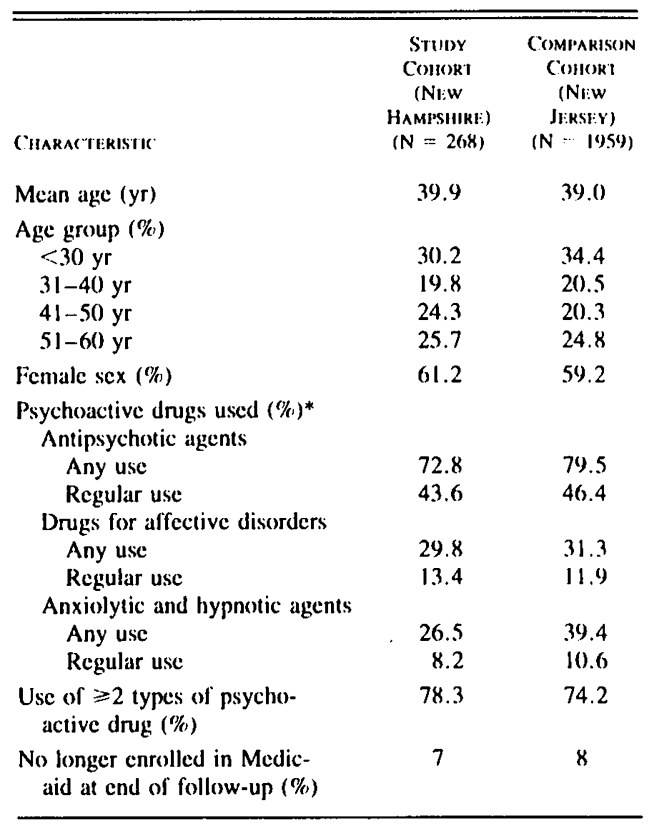

*Any use is defined as $>1$ prescription in the base-line year and regular use as $\triangleq 1$ prescription per cuarter in the base-line year (July 1980 ) through June 1981).
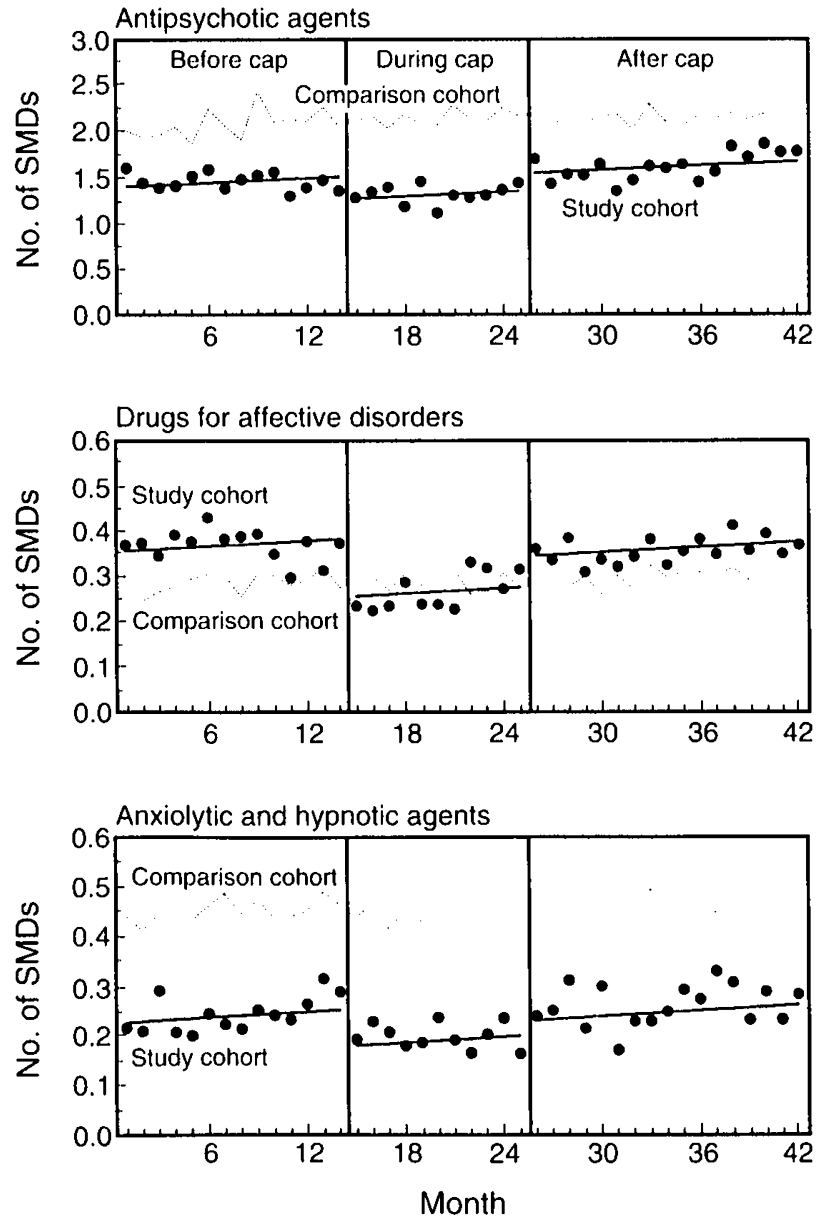

Figure 1. Standard Monthly Doses (SMDs) per Patient of Antipsychotic Agents, Drugs for Affective Disorders, and Anxiolytic and Hypnotic Agents Whose Cost Was Reimbursed by Medicaid in the Study Cohort (New Hampshire; $N=268$ ) and the Comparison Cohort (New Jersey; $N=1959$ ).

The fitted trend lines for the study cohort show predicted values for segmented time-series regressions. After the cap was discontinued, a copayment of $\$ 1$ per prescription was instituted.

aid-reimbursed and CiMHCi-provided antipsychotic agents were included, the average use per patient per month was (0.91 SMD before the cap was instituted, $1.24 \mathrm{SMD}$ s while it was in effect, and $0.80 \mathrm{SMD}$ after it was discontinued.

\section{Use of CMHCs and Admissions to State Psychiatric Hospitals}

As illustrated in Figure 3 , after a moderate decline at CMHC: I from 7.6 to 4.3 visits to the center per patient per month, the number of visits increased abruptly when the cap was put into effect, reaching 7.5 visits by the end of the cap period (increase in trend, $0.6 \pm 0.1$ visit per patient per month 157 percent]; $\mathrm{P}<0.0(01)$. When the cap was withdrawn, the number of visits declined to 6.4 per patient per month by the end of the $17-m o n t h$ follow-up period $(\mathrm{P}<0.001)$. $\Lambda \mathrm{t}$ CMHC: 2, the institution of the (ap) was associated with an immediate increase in the number of visits 


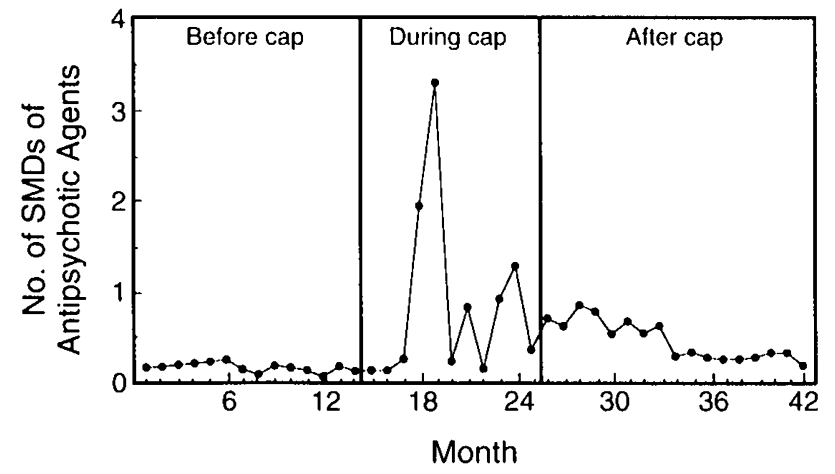

Figure 2. Standard Monthly Doses (SMDs) of Antipsychotic Agents Administered per Patient at CMHC 1 to Members of the Study Cohort $(\mathrm{N}=29)$.

The average amount of antipsychotic agents administered at and paid for by the CMHC was equivalent to 0.18 SMD per patient per month before the cap was instituted; this increased by a mean $( \pm S E)$ of $0.93 \pm 0.33$ SMD while the cap was in effect $(P=0.008)$ and declined gradually to base-line levels after the cap was discontinued.

(increase in level, $1.0 \pm(0.4$ visits, $\mathrm{P}=0.01)$ and an increase in slope $(0.2 \pm 0.04$ visit per patient per month [4:3 percent, $\mathrm{P}<0.001$ ), which continued to the end of the study period.

We hypothesized that exacerbations of schizophrenic symptoms would result in an increased use of emergency mental health services and in more partial hospitalizations. Before the cap went into effect, study patients used no emergency services at CMHG 1; while the cap was in place, there was 0.03 service per patient per month $(\mathrm{P}=0.002$ for the change in level) (Fig. 4); by three months after the cap was discontinued, the use of emergency services had returned to zero. Similarly, the trend in the use of emergency services increased markedly at CMHC: 2, from 0.002 per patient per month at base line to 0.26 at the end of the cap period (Fig. 4) (increase in trend, 0.02 service per patient per month; $\mathrm{P}<0.001)$. The use of emergency services declined after discontinuation of the policy.

At CMHC: 1, the number of days of partial hospitalization increased substantially, from 3.4 per patient per month before the cap was imposed to 4.6 at the end of the period during which the cap was in effect, falling again to 2.3 after the copayment was introduced (no time-series analysis was carried out because of a statistically unstable pre-cap series). $\Lambda \mathrm{t}$ CMHC 2, the number of days of partial hospitalization increased from 1.5 at base line to 2.9 at the end of the cap (increase in trend, $0.17 \pm 0.04$ per patient per month; $\mathrm{P}<0.001)$; no further change was observed during the copayment period that followed the discontinuation of the cap.

Analyses of all study patients in New Hampshire $(n=268)$ detected no change in the rate of admission to the state psychiatric hospital. Before the cap was implemented, the admission rate was 0.38 per patientyear; while the cap was in effect, it was 0.41 ; and after the cap was discontinued, it was 0.38 (P not significant for any of the three comparisons).

\section{Economic Effects}

The base-line Medicaid drug expenditure was $\$ 21.97$ per study patient per month in the 14 months before the cap was imposed; expenditures decreased abruptly by $\$ 5.14 \pm 0.67$ per patient per month during the period of the cap (a decrease in level of 23 percent, $\mathrm{P}<0.001)$. The increase in costs associated with the cap was about $\$ 139$ per patient per month at the two (iMHCis we studied $(\$ 1,530$ per patient during the 11 -month cap period), based on a weighted average of estimated increases in the use of mental health services at the study CMHCis (1.5 visits per patient per month) and the average unit charge for these services to third-party payers at the time (\$92). Claims data showed that an estimated 95 pereent of study patients $(n=255)$ had at least one visit to a CiMHC. The estimated increase in the statewide cost of mental health services while the cap was in effect was $\$ 390,000$, based on figures extrapolated from the sampled CMHCis. Assuming conservatively that the increased statewide costs were one third lower than those observed in the two CMHCs we studied, the increases in the costs of mental health services exceeded the savings in drug expenditures by a factor of
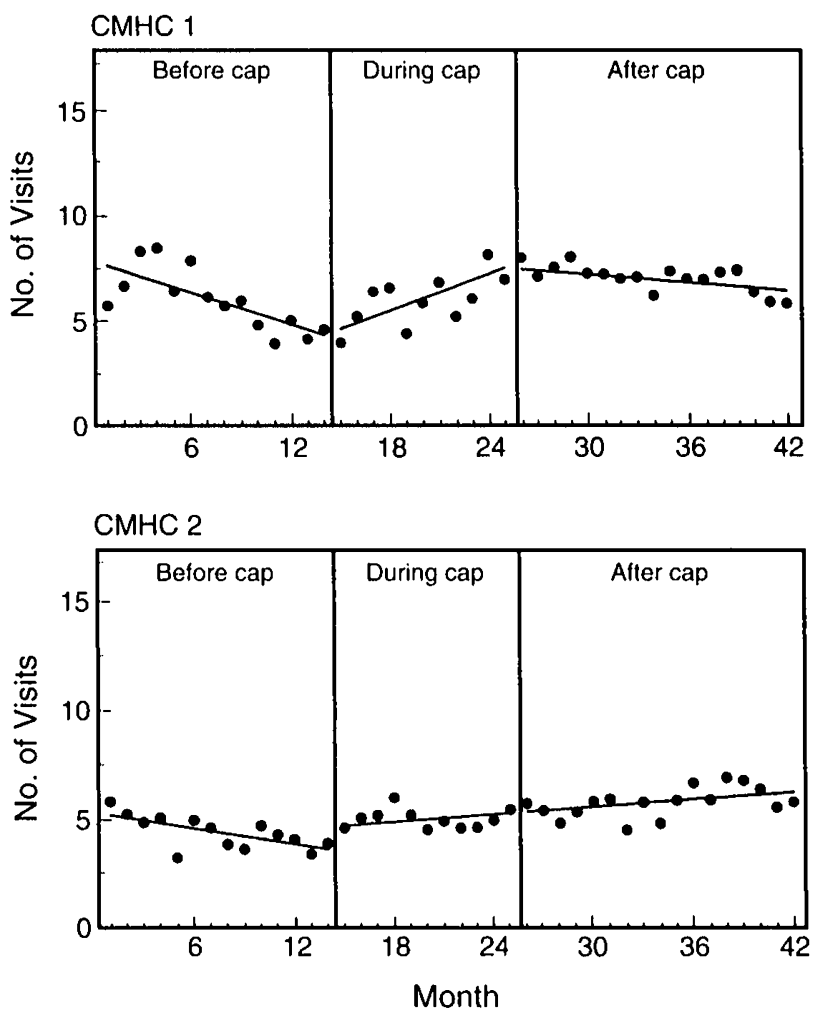

Figure 3. Visits to $\mathrm{CMHC} 1$ and $\mathrm{CMHC} 2$ per Patient per Month in the Study Cohort.

A total of 29 patients received services at CMHC 1, and 49 received services at $\mathrm{CMHC} 2$. The fitted trend lines show predicted values for segmented time-series regressions. 

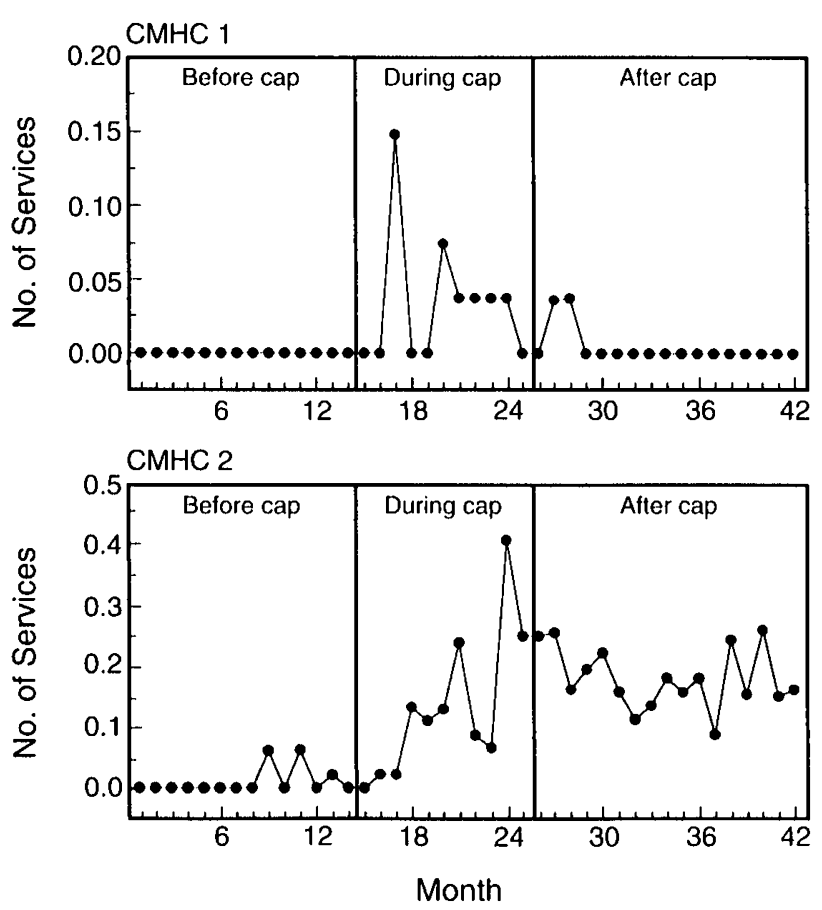

Figure 4. Emergency Mental Health Services per Patient per Month at CMHC $1(\mathrm{~N}=29)$ and CMHC $2(\mathrm{~N}=49)$.

more than 17. Moreover, we probably underestimated these costs because of the lack of datat on administrative costs and the costs of the psychoactive drugs provided free at (iMHCis, other unobserved expenditures (for example, cost shifting to Medicare, the criminaljustice system, family efforts to compensate for disruptions in care, and possibly increased cost of treating the approximately 30 percent of patients with schizophrenia not identified by our algorithm), ${ }^{31}$ and intangible costs, such as increases in pain, suffering, and the risk of suicide among patients, that were associated with exacerbations of schizophrenic illness.

\section{Discussion}

We previously reported a direct relation between the New Hampshire Medicaid drug-payment cap and both the reduced use of essential therapies and increased institutionalization of frail elderly persons." In the present study, we examined the effects of this policy on another vulnerable population: low-income adult patients with schizophrenia who were living in the community. Our results strongly suggest that the restriction on payment for psychoactive medication caused immediate and sustained reductions in the use of antipsychotic drugs, antidepressants and lithium, and anxiolytic and hypnotic agents. 'The lower base-line use of antipsychotic agents among New Hampshire patients, as compared with patients in New Jersey, suggests that psychiatrists in New Hampshire were already reducing doses to minimize adverse cffects, a finding that is consistent with recent positive evaluations of New Hampshire's public: mental health system. ${ }^{32}$
We detected no changes related to the cap in the rates of admission to the state psychiatric hospital. However, there was a significant increase in visits to CMHCs; an increase in the administration of antipsychotic agents at the CMHCs that were paid for by the state mental health system; and increases in the use of emergency mental health services, partial hospitalizations, and doses of antipsychotic agents given at the CMHCs. The sudden decline in the number of patients given psychoactive medications at the CiMHCis and the downward trends in the use of most acute mental health services after the (ap) was discontinued further support the hypothesis that the limit on drug benefits increased patients' agitation or exacerbated schizophrenic symptoms, thereby increasing the use of expensive acute care services. Continued higher rates of partial hospitalization and increased numbers of outpatient visits at CMHC 2 suggest that some local effects of the cap continued even after its withdrawal. These consequences may be due to the need for continued surveillance to stabilize the condition of patients after relapse, the difficulty of changing administrative mechanisms once they are in place, and the effects of the newly required copayment.

Could some other factor have caused the increased use of acute mental health care services?' This is unlikely, since such a confounder would have had both to increase use after the 14-month base-line period and to reduce it again 11 months later. In addition, none of the directors and staff members of New Hamp)shire CiMHC's could suggest alternative explanations. The fact that admissions to the state psychiatric hospital did not increase is consistent with state mental health policies that strongly discouraged such admissions.

Could the observed changes merely reflect patients' efforts to gain access to medications rather than changes in their mental health status? 'This explanation is unlikely, because most patients received oncmonth supplies of medications and werc already visiting the CMHC's about once a week before the cap was imposed (Fig. 3). 'Thus, additional visits were not needed to obtain medications. It is more likely that the increased use of services, especially the higher rate of use of partial hospitalization and emergency mental health services, represents a response to acute exacerbation of illness, although the exact reasons for the increases in acute care services remain unknown.

Case reports obtained from state mental health records corroborate these impressions. lor example, during the period when the cap was in eflect a middleaged woman with schizophrenia was admitted to the New Hampshire Hospital on an emergency basis because of extreme agitation. At admission, her medication regimen included an antipsychotic agent, an antiparkinsonian drug, insulin, and a cardiac medication. The reasons for admission included diabetic ketoacidosis precipitated by her discontinuation of insulin in favor of continuing her other three medications. 
What are the policy implications of these findings? First, our study suggests that even small reductions in reimbursement for effective medications (c.g., \$5 per month) can have substantial unintended effects on low-income people with chronic mental illnesses. Medications are frequent targets for cost-containment programs. However, the literature does not support the view that cost sharing or arbitrary limits on drugreimbursement bencfits reduce overall costs while maintaining essential care for low-income, chronically ill populations.'

Second, our results challenge once again the assumption that changes in one sector of care can have simple and isolated effects. ${ }^{5,6}$ Vulnerable patients have sustained needs in a system of care that is in fragile equilibrium. Even slight perturbations in their support system can have direct consequences and also secondary or compensatory effects. In this study, the new equilibrium included costly increases in the use of acute services.

Third, our data suggest that important changes in health policies affecting vulnerable populations should be implemented under close scientific scrutiny. $\Lambda$ t the very least, policy changes that pose substantial risks should undergo careful evaluation before their widespread adoption. Because policy changes often occur rapidly, faster funding mechanisms are needed to allow prospective studies and direct measures of health outcomes.

The results of this study illustrate the need for a mechanism to disseminate timely, objective, and concise information on the positive and negative effects of cost-containment policies to state legislators and administrators when decisions are being made. Political factors often predominate at such times, but scientific data also have an important role. For example, a report in the Wall Street Journal on the effects of the New Hampshire cap on the institutionalization of frail clderly patients ${ }^{-1}$ was successfully used to prevent the reintroduction of the policy by the legislature in 1990 . $\Lambda$ s the quality of health policy studies increases, attention should focus on disseminating relevant findings to organizations whose decisions affect the stability of vulnerable patients and the costs and outcomes of their care.

We are indebted to the Medicaid programs of New Hampshire and New Jersey for facilitating our access to the Medicaid claims data; to the New Hampshire Department of Mental Health, the Community Mental Health Centers, and the New Hampshire Hospital for providing and helping to interpree the data on mental health treatment episodes; to Sharon Hawley for abstracting clinical data; to Dan (Gilden of Jen Associates for statistical and data-processing support; to Leon L̈̈senberg, Thomas Imui, Helene Lipton, Harold Schwartz, Gordon Schiff, Jonathan Lomas, and Paul Widem for their helpful comments on an carlier version of this paper; and to Ann Payson and Laura (Goldberg for assisting in the preparation of the figures and the manuscript.

\section{References}

1. Soumerai SB, Ross-Degnan D, Fortess EE, Abelson J. A critical analysis of studies of state drug reimbursement policies: research in need of discipline. Milbank Q 1993:71(2):217-52.
2. Haaijer-Ruskamp FM, Dukes MNG. Drugs and money: the problem of cost containment. WHO Collaboration Centre for Clinical Pharnacology and Drug Policy Science. Groningen, the Netherlands: Styx Publications, 1991.

3. Lohr KN, Brook RH, Kamberg CJ, et al. Use of medical care in the Rand Health Insurance Experiment: diagnosis- and service-specific analyses in a randomized controlled trial. Med Care 1986;24:S1-S87.

4. Luric N, Ward NB, Shapiro MF, Gallego C, Vaghaiwalla R, Brook RH Termination of Medi-Cal benelits: a follow-up study one year later. N Engl J Med 1986;314:1266-8.

5. Soumerai SB, Ross-Degnan D, Avorn J, McLaughlin TJ, Choodnovskiy I. Effects of Medicaid drug-payment limits on admission to hospitals and nursing homes. N Engl J Med 1991;325:1072-7.

6. Schroeder SA. Cantor JC. On squeczing balloons: cost control fails again. $\mathrm{N}$ lingl J Med 1991:325:1099-100.

7. International Pilot Study of Schizophrenia Report. Vol. 1. Geneva: World Health Organization, 1973.

8. World Health Organization. Schizophrenia: an international follow-up study. Chichester, England: Wiley, 1979.

9. Jablensky A. Epidemiology of schizophrenia. In: Bebbington P. McGuffin P, eds. Schizophrenia: the major issues. Oxford, England: Heinemann Professional, 1988:19-35.

10. Licherman $\mathrm{AA}$, Coburn $\mathrm{AF}$. The health of the chronically mentally ill: a review of the literature. Community Ment Health J 1986;22:10416.

11. Andrews G, Hall W, Goldstein G. Lapsley H, Bartels R, Silove D. The economic costs of schizophrenia: implications for public policy. Arch Gen Psychiatry 1985:42:537-43.

12. Wanderers in a promised land: the chronically mentally ill and deinstitutionalization. Med Care 1984;22:Suppl:S1-S60.

13. Shapiro S. Skinner EA. Kramer M. Steinwachs DM, Regier DA. Measuring need for mental health services in a general population. Med Care 1985:23:1033-43.

14. Sharfstein SS, Stoline AM. Reform issues for insuring mental health care Health Aff (Millwood) 1992:11(3):84-97.

15. Mechanic D, Rochefort DA. A policy of inclusion for the mentally ill. Health Aff (Millwood) 1992:11(1):128-50.

16. Kane JM, Marder SR. Psychopharmacologic treatment of schizophrenia Schizophr Bull 1993:19:287-302.

17. Johnson DAW. Drug treatment of schizophrenia. In: Bebbington P. McGuftin P. eds. Schizophrenia: the major issues. Oxford, England: Heinemann Professional, 1988:158-71.

18. Crane GlE. Clinical psychopharmacology in its 20 th year: late, unanticipated effects of neuroleptics may limit their use in psychiatry. Science 1973; 181:124-8.

19. Ellenbrock BA. Treatment of schizophrenia: a clinical and preclinical evaluation of neuroleptic drugs. Pharmacol Ther 1993:57:1-78

20. Davis JM, Gierl B. Pharmacological treatment in the care of schizophrenic patients. In: Bellack AS, ed. Treatment and care for schizophrenia. Orlando, Fla.: Grunc \& Stratton, 1984.

21. Ennia SJ, Coyle JT. Neuroleptics. In: Coyle JT, Enna SJ, eds. Neuroleptics: neurochemical, behavioral and clinical perspectives. New York: Raven Press, 1983:1-14

22. Soumerai SB, Avorn J, Ross-Degnan D, Gortmaker S. Payment restrictions for prescription drugs under Medicaid: effects on therapy, cost, and equity. N lingl J Med 1987;317:550-6.

23. Cook TD. Campbell DT. Quasi-experimentation: design and analysis issues for field seltings. Boston: Houghton Mifflin. 1979.

24. Mohr L.B. Impact analysis for program evaluation. Newbury Park, Calif.: Sage Publications, 1992.

25. Ray WA. Griftin MR. Use of Medicaid data for pharmacoepidemiology. Am J Epidemiol 1989:129:837-49.

26. Soumerai SB, Ross-Degnan D, Gortmaker S, Avorn J. Withdrawing payment for nonscientific drug therapy: intended and unexpected effects of a large-scalc natural experiment. JAMA 1990;263:831-9.

27. Ross-Degnan D. Soumerai SB, Fortess EE, Gurwitz. JH. Examining product risk in context: market withdrawal of zomepirac as a casc study. JAMA 1993:270:1937-42.

28. Luric N, Popkin M, Dysken M, Moscovice I, Finch M. Accuracy of diagnoses of schizophrenia in Medicaid claims. Hosp Community Psychiatry 1992:43:69-71

29. Gillings D, Makuc D. Siegel E. Analysis of interrupted time series mortality trends: an eximple to evaluate regionalized perinatal care. Am J Public Health 1981:71:38-46.

30. Baldessarini RJ, Cohen BM, Teicher MH. Signiticance of neuroleptic dose and plasma level in the pharmacological treatment of psychoses. Arch Gen Psychiatry 1988;45:79-91.

31. McGuire TG. Measuring the economic costs of schizophrenia. Schizophr Bull 1991:17:375-88

32. Torrey EF, Erdman K, Wolfe SM, Flynn LM. Care of the seriously mentally ill: a rating of state programs. Washington, D.C.: Public Citizen Health Research Group. National Alliance for the Mentally III, 1990. 